\title{
CARACTERIZAÇÃo DE GENÓTIPOS DE Citrus spp. ATRAVÉS DE MARCADORES RAPD
}

\author{
CHARACTERIZATION OF CITRUS GENOTYPES (Citrus spp) USING RAPDs MARKERS
}

\author{
Marinês Bastianel $^{1}$ Ana Lúcia Cunha Dornelles ${ }^{1}$ Marcos Antonio Machado $^{2}$ Ester Wickert $^{1}$ \\ Simone de Farias Maraschin ${ }^{1}$ Helvécio Della Coletta Filho ${ }^{2}$ Gilmar Schäfer $^{1}$
}

\section{RESUMO}

\begin{abstract}
Em programas de melhoramento de citros, a caracterização adequada dos recursos genéticos disponíveis é de grande importância, principalmente devido às características biológicas da cultura, como a heterozigosidade, a embrionia nucelar e o longo ciclo reprodutivo. A facilidade com que ocorrem hibridações (interespecíficas e intergenéricas) $e$ a embrionia nucelar favoreceram a formação e a preservação de novas combinações, classificadas como espécies. Neste estudo, marcadores RAPDs foram utilizados para analisar 15 acessos de Citrus spp., sendo quatro variedades de laranjeiras doce $(\boldsymbol{C}$. sinensis Osbeck), quatro tangerineiras (C. reticulata Blanco, $\boldsymbol{C}$. nobilis Loureiro, $\boldsymbol{C}$. sunki Loureiro e C. deliciosa Tenore), uma laranjeira azeda (C. aurantium L.), um pomeleiro (C. paradisi Macf.), uma torangeira (C. grandis Osbeck), uma cidreira (C. medica L.), uma limeira ácida (C. latifolia) e dois híbridos (Citrus clementina T. $x$ (C. tangerina T. $x$ C. paradisi Macf.)). Doze sequências iniciadoras aleatórias foram utilizadas para estudar os 15 genótipos, encontrando-se um grau de similaridade mínimio de 0,81 ("Simple Matching") entre as tangerineiras. Os menores graus de similaridade foram encontrados entre as espécies de Citrus menos aparentadas (C. medica, $\boldsymbol{C}$. grandis $e$ C. latifolia). As quatro cultivares de laranjeiras doces não puderam ser diferenciadas pelos marcadores RAPD utilizados, apresentando similaridade máxima.
\end{abstract}

Palavras-chave: Citrus, melhoramento, diversidade.

\section{SUMMARY}

In citrus improvement programs the characterization of the available genetic resources is of great importance, mainly concerning biological characteristics of the culture, as the heterozigosity, nucellar the embriony and long reproductive cycle. Favored by nucellar embriony interespecific and intergeneric hybridizations and genotypes preservation happen easily. RAPDs markers were used to analyze 15 Citrus spp., four sweet orange (C. sinensis Osbeck), (C. medica, C. grandis e C. latifolia), four mandarins (C. reticulata Blanco, $\boldsymbol{C}$. nobilis Loureiro, C. sunki Loureiro e C. deliciosa Tenore), a sour orange (C. aurantium L.), a grapefruit (C. paradisi Marcf.), a pummelo (C. grandis Osbeck), a cidra (C. medica L.), a lime (C. latifolia) and two hybrids (Citrus clementina T. $x$ (C. tangerina T. $x$ C. paradisi Macf.)). Genetic similarities of 15 Citrus genotypes obtained with twelve random primers, indicated a minimum similarity degree of 0.81 (simple matching) among the mandarins. Lower similarity degrees were obtained among less related Citrus species (C. medica, $\boldsymbol{C}$. grandis e $\boldsymbol{C}$. latifolia). The four varieties of sweet oranges $(\boldsymbol{C}$. sinensis Osbeck) could not be differentiated by RAPD markers, showing maximum similarity.

Key words: Citrus, breeding, diversity.

\section{INTRODUÇÃO}

Os citros apresentam uma taxonomia muito complexa, principalmente com relação ao número de espécies que constituem o gênero Citrus e gêneros correlacionados. É possível que a grande diversidade observada entre as plantas cítricas cultivadas, responsável pela sua complexa taxônomia, seja oriunda de mutações e de alterações cromossômicas estruturais ancestrais, preservada através da embrionia nucelar (IWAMASA \& NITO, 1988). Muitos biótipos, classificados como espécies podem ter sido originados de hibridizações interespecíficas. A embrionia nucelar foi provavelmente responsável pela preservação destes híbridos, possibilitando um isolamento reprodutivo destas novas combinações (CAMERON \& FROST, 1968).

\footnotetext{
${ }^{1}$ Departamento de Horticultura e Silvicultura, Faculdade de Agronomia, Universidade Federal do Rio Grande do Sul, CP 776, 91501 970 Porto Alegre, RS, Brasil. Correspondências para Ana Lúcia Cunha Dornelles. E-mail: alcunha@ vortex.ufrgs.br

${ }^{2}$ Centro de Citricultura Sylvio Moreira, IAC, Cordeirópolis, SP, Brasil. 
Vários sistemas de taxonomia para o gênero Citrus têm sido propostos. Esses sistemas diferem principalmente quanto ao número de espécies que compõem os vários gêneros. Hoocker, de acordo com a revisão de SWINGLE \& REECE (1967), em 1875 classificou o gênero Citrus em somente quatro espécies, enquanto Engler, em 1931, propôs 11 espécies para o gênero e Swingle, em 1943, subdividiu o gênero Citrus em dois subgêneros: Papeda e Citrus, com 16 espécies. Tanaka, citado por SCORA (1975), em 1961 propôs a existência de 159 espécies para os citros. Essas diferenças com relação ao número de espécies deveram-se ao fato de que Swingle considera muitos dos representantes desse grupo como híbridos, enquanto Tanaka os considera como espécies verdadeiras.

Embora estes dois últimos sistemas de classificação tenham sido os mais utilizados na sistemática dos Citrus, vários autores sugerem números de espécies diferentes daqueles propostos por Swingle e Tanaka, baseados em estudos químicos, bioquímicos, morfológicos e moleculares (BARRET \& RHODES, 1976; HANDA et al., 1986; GREEN et al., 1986).

BARRET \& RHODES (1976), estudando a morfologia das plantas, sugeriram, baseados em 146 marcadores, a existência de três grupos de importância comercial em Citrus: O grupo de Citrus medica $L(C$. medica L., $C$. aurantifolia L. e $C$. limon Burm.f.), o grupo de Citrus reticulata Blanco (C. reticulata Blanco, $C$. sinensis $\mathrm{L}$. Osbeck, $\boldsymbol{C}$. paradisi Marcf., C. aurantium L. e C. jambhiri Lush.) e o grupo $\boldsymbol{C}$. grandis (L.) Osbeck.

Estudos da Fração I das proteínas de folhas também levaram HANDA et al. (1986) a considerarem que Citrus medica L., $C$. reticulata Blanco e $\boldsymbol{C}$. grandis (L.) Osbeck são as espécies originais dos citros. Estes resultados foram apoiados por estudos com isoenzimas e marcadores baseados em DNA (GREEN et al., 1986; TORRES et al., 1978; ROOSE, 1988; LURO et al., 1992; YAMAMOTO $\boldsymbol{e t}$ al., 1993, COLETTA FILHO et al., 1998).

Em citros, marcadores moleculares têm sido amplamente utilizados em um grande número de espécies para fins de caracterização de germoplasmas, estudos taxonomicos e filogenéticos, mapeamento e identificação de mutantes, entre outros (LURO et al., 1992; CAI et al., 1994; LURO et al., 1995; MACHADO et al. 1996; BASTIANEL et al., 1998; COLETTA FILHO et al., 1998).
O presente trabalho teve como objetivo a caracterização de 15 genótipos de citros, presentes na coleção de citros da Estação Experimental Agronomica da Universidade Federal do Rio Grande do Sul (EEA/UFRGS), em Eldorado do Sul, Rio Grande do Sul (Brasil) com a utilização do marcador molecular RAPD.

\section{MATERIAIS E MÉTODOS}

As plantas utilizadas no presente estudo pertencem à coleção de citros da EEA/UFRGS (Tabela 1). Aproximadamente $100 \mathrm{mg}$ de folhas jovens foram coletadas de cada planta para a análise RAPD.

\section{Extração do DNA total}

O DNA total foi extraído segundo metodologia descrita por MURRAY \& THOMPSON (1980), e utilizada por BASTIANEL et al. (1998). A quantificação e a qualificação do DNA genômico foram efetuadas segundo metodologia descrita por SAMBROOK et al. (1989).

\section{Reações de amplificação e eletroforese}

As reações de amplificação foram preparadas em um volume de $12,3 \mu \ell$ contendo: $1,3 \mu \ell$ de tampão 10x (100mM Tris-HCl PH 8,3; $500 \mathrm{mM} \mathrm{KCl} ; 20 \mathrm{mM}$ de $\mathrm{MgCl} 2$ e $0,01 \%$ de gelatina); 200mM de cada nucleotídeo dATP, dTTP, dCTP e dGTP (Gibco); 15ng da seqüência iniciadora de 10 nucleotídeos (Operon), 15ng do DNA genômico e 1,5 unidades da enzima Taq polimerase (Cembiot/RS). $15 \mu \ell$ de óleo mineral (Sigma) foi adicionado para evitar evaporação.

Tabela 1 - Genótipos presentes na coleção de citros da EEA/UFRGS que foram utilizados para análises RAPD.

\begin{tabular}{|c|c|}
\hline Nome científico segundo TANAKA (1954) & Nome comum \\
\hline Citrus clementina $\times(C$. tangerina $\times C$. paradisi $)$ & Tangerineira 'Lee' \\
\hline Citrus reticulata & Tangerineira 'Ponkan' \\
\hline C. nobilis & Tangerineira 'de Umbigo' \\
\hline C. aurantium & Laranjeira azeda \\
\hline C.paradisi & Pomeleiro 'Foster' \\
\hline C. sinensis & Laranjeira 'Caipira' \\
\hline C. latifolia & Limeira ácida 'Tahiti' \\
\hline C. sunki & Tangerineira 'Sunki' \\
\hline C. medica & Cidreira 'of Comerce' \\
\hline C. grandis & Toranjeira 'Paraíso' \\
\hline C. sinensis & Laranjeira 'Valência' \\
\hline Citrus clementina $\times(C$. tangerina $\times$ C. paradisi $)$ & Tangerineira 'Osceola' \\
\hline C. sinensis & Laranjeira 'Cipó' \\
\hline C. sinensis & Laranjeira 'Pera do Rio' \\
\hline C. deliciosa & Tangerineira 'Caí' \\
\hline
\end{tabular}

Ciência Rural, v. 31, n. 5, 2001. 
A amplificação foi conduzida em termocicladores MJ Research Thermocycler, programados para 36 ciclos de um minuto a $92^{\circ} \mathrm{C}$, um minuto a $36^{\circ} \mathrm{C}$ e dois minutos a $72^{\circ} \mathrm{C}$, acrescidos de 10 minutos a $72^{\circ} \mathrm{C}$ ao final do último ciclo.

Os padrões de amplificação foram visualizados através de eletroforese em gel de agarose $1,4 \%$, corado com brometo de etídeo $(0,5 \mathrm{ng} / \mathrm{m} \ell)$ e fotografado no sistema Eagle eye (STRATAGENE).

\section{Análise dos dados \\ O grau de similaridade entre os} genótipos foi estimado através da presença ou ausência de bandas (polimórficas e monomórficas). Os tamanhos dos fragmentos foram estimados por comparação com o marcador $1 \mathrm{~Kb}$ DNA ladder. O peso molecular das bandas obtidas nas duas análises foi estimado com o uso do software GEL (SCHAFFER \& SEDEROFF, 1989). Os dados foram analisados utilizando-se o sistema de taxonomia numérica e análise multivariada NTSYS (Numerical Taxonomia and Multivariate Analysis System) - versão 1.7 (ROHLF, 1992). A matriz de similaridade foi gerada usando o coeficiente SM ("Simple Matching") e o dendograma construído pelo método UPGMA ("Unweighted Pair Group Method with Arithmetic Average").

\section{RESULTADOS E DISCUSSÃO}

Os doze oligonucleotídeos iniciadores utilizados produziram um total de 85 bandas, sendo 64 polimórficas. A relação dos "primers" utilizados, bem como do número de fragmentos monomórficos e polimórficos produzidos, foram mostrados na tabela 2. Os fragmentos amplificados variaram de 300 a 3000 pares de bases.

Números diferentes de fragmentos polimórficos por oligonucleotídeo iniciador foram obtidos, variando de três (OPAB03 e OPAB05) a 10 fragmentos (OPM06) (Tabela 2). Este alto número de polimorfismo por oligonucleotídeo iniciador possivelmente tenha ocorrido devido à distância genética dos materiais estudados, tendo em vista que as três espécies consideradas por muitos autores como as espécies ancestrais dos citros (C. medica L., C. grandis [L] Osbeck $e$ C. reticulata Blanco) estão incluídas neste estudo.

Marcadores espécie-específicos foram encontrados para a toranjeira (OPAB03_1063pb; OPN20_2168pb; e OPI11_873pb; limeira ácida 'Tahiti' (OPM06_395pb); pomeleiro (OPM06_663pb;
Tabela 2 - Relação dos oligonucleotídeos iniciadores utilizados e número de bandas geradas por oligonucleotídeo iniciador na análise genética de 15 genótipos de citros.

\begin{tabular}{lccc}
$\begin{array}{l}\text { Oligonucleotídeo } \\
\text { iniciador }\end{array}$ & Seqüência & $\begin{array}{c}\text { Fragmentos } \\
\text { amplificados }\end{array}$ & $\begin{array}{c}\text { Fragmentos } \\
\text { polimórficos }\end{array}$ \\
\hline OPAB02 & 5' CCGTCGGTAG 3' & 06 & 05 \\
OPAB03 & 5' TGGCGCACAC 3' & 04 & 03 \\
OPAB04 & 5' GGCACGCGTT 3' & 09 & 07 \\
OPAB05 & 5' CCCGAAGCGA 3' & 05 & 04 \\
OPB12 & 5' CCTTGACGCA 3' & 09 & 07 \\
OPG10 & 5' AGGGCCGTCT 3' & 04 & 03 \\
OPH04 & 5' GGAAGTCGCC 3' & 07 & 07 \\
OPH09 & 5' TGTAGCTGGG 3' & 07 & 04 \\
OPI11 & 5' ACATGCCGTG 3' & 10 & 06 \\
OPI12 & 5'AGAGGGCACA 3' & 05 & 04 \\
OPM06 & 5' CTGGGCAACT 3' & 14 & 10 \\
OPN20 & 5' GGTGCTCCGT 3' & 05 & 04 \\
Total & & 85 & 64 \\
\hline
\end{tabular}

OPAB05_857pb; OPAB04_663pb); cidreira (AB05_1439pb; OPH04_2441pb), laranjeira azeda (OPH04_1303pb) e para a tangerineira 'Ponkan' (OPN20_872pb).

Os marcadores genéticos OPI11_934pb, OPB12_1391pb e OPB12_756pb foram encontrados nas laranjeiras doce, azeda e pomeleiro 'Foster' e também esteve presente na toranjeira. Esta similaridade sugere um parentesco entre estas espécies. SCORA (1975) e BARRET \& RHODES (1976) sugeriram que estas espécies tenham a toranjeira (Citrus grandis [L] Osbeck) como espécie ancestral. Estes autores consideram que as laranjeiras doce (C. sinensis Osbeck) e a laranjeira azeda (C. aurantium L.) sejam híbridas de toranjeira (C. grandis) e tangerineiras (C. reticulata Blanco), enquanto o pomeleiro ( $\boldsymbol{C}$. paradisi Macf.) é considerado um provável híbrido de $\boldsymbol{C}$. sinensis e $\boldsymbol{C}$. grandis. Os marcadores OPAB02_2058pb presente nas laranjeiras, pomeleiro e em $\boldsymbol{C}$. reticulata; OPAB2_2217pb presente nas laranjeiras, pomeleiro e nas tangerineiras e OPH09_1465pb presentes nas laranjeiras e em $\boldsymbol{C}$. grandis, também apóiam estes resultados.

Os marcadores OPB12_1058pb e OPM06_324pb comuns à limeira ácida 'Tahiti' ( $\boldsymbol{C}$. aurantifolia Swing.) e à cidreira (C. medica L.); e os marcadores OPI11_934pb e OPG10_575pb comuns ao 'Tahiti' e à toranjeira (C. grandis) como sugerem a origem híbrida da lima ácida Tahiti, tendo a cidreira e a toranjeira como possíveis parentais. $\mathrm{O}$ marcador OPM06_395pb, específico para a limeira ácida Tahiti e não encontrado na toranjeira e cidreira, possivelmente é oriundo de um terceiro ancestral, como sugerido por SCORA (1975) e BARRET \& RHODES (1976) que atribuíram uma 
origem híbrida composta por três espécies para as limeiras ácidas $(\boldsymbol{C}$. grandis, $\boldsymbol{C}$. medica e uma espécie do gênero Microcitrus).

$\mathrm{O}$ agrupamento dos coeficientes SM pelo método UPGMA resultou no dendrograma (Figura 1), onde os genótipos estudados foram separados em dois grandes grupos: grupo A formado pelas tangerineiras (Lee, Sunki, Ponkan, de Umbigo, Cai e Osceola); pomeleiro Foster, laranjeiras doce (Caipira, Valência, Pera do Rio e Cipo) e laranjeira Azeda e o grupo B formado pela limeira ácida Tahiti, cidreira Of Comerce e toranjeira Paraíso. As laranjeiras doce e azeda, bem como a pomeleiro consideradas híbridas por alguns autores (SCORA, 1975; BARRET \& RHODES, 1976) formaram subgrupo intermediário dentro do grupo A.

Dentro do grupo das tangerineiras, o coeficiente de similaridade mínimo foi de 0,81 (Figura 1), indicando um alto grau de similaridade genética entre os genótipos deste grupo. Estes resultados estão de acordo com os obtidos por COLETTA FILHO et $\boldsymbol{a l}$. (1998) que, ao utilizarem RAPDs para comparar diferentes genótipos de tangerineiras, encontraram índices de similaridade (Jaccard) superiores a 0,77. As tangerineiras 'Caí' ( $\boldsymbol{C}$. deliciosa Tenore) e 'De Umbigo' (C. nobilis Loureiro) foram as espécies deste grupo que apresentaram maior grau de similaridade genética $(0,90)$.

Estudos genéticos têm sugerido que as tangerineiras são muito próximas entre si. TORRES et al. (1978) observaram baixo nível de polimorfismo de quatro locos isoenzimáticos entre 33 cultivares de tangerinas. MACHADO et al (1996) encontraram baixo polimorfismo RAPD entre acessos de tangerinas do Mediterrâneo (C. deliciosa

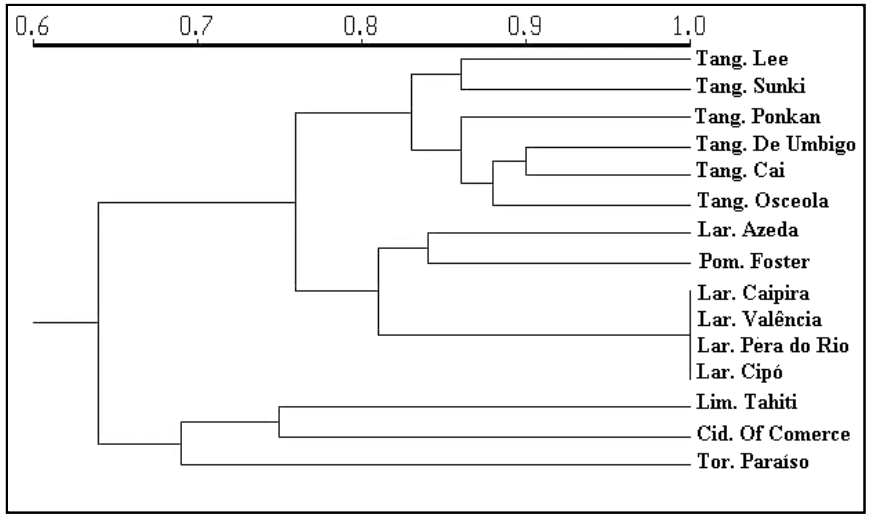

Figura 1 - Análise de agrupamento pelo método UPGMA ("Unweighted Pair Group Method with Arithmetic Average") entre genótipos presentes na coleção de citros da EEA/UFRGS (Estação Experimental Agronomica da Universidade Federal do Rio Grande do Sul).
Tenore) sugerindo que este grupo é híbrido de tangerineira comum (C. reticulata Blanco). Estes autores sugeriram que hibridações e mutações possivelmente foram fatores importantes na evolução destas espécies sendo responsáveis pela grande diversidade fenotípica e genética encontrada neste grupo.

Da mesma forma, SAWAZAKI et al. (1992) analisando 7 sistemas enzimáticos encontraram diferenças entre as tangerineiras 'Clementina' e 'Ponkan' em relação a 'Sunki' e a 'Cleópatra', apesar do baixo número de alelos por loco e baixa heterozigosidade, confirmando que a diversidade varietal das tangerineiras é devida a hibridações.

As tangerineiras 'Lee' e 'Osceola', híbridos resultantes de um mesmo cruzamento (HODGSON, 1967), apresentaram $81 \%$ de similaridade genética. Apesar de ser um alto índice de similaridade, este valor foi inferior ao encontrado entre estas e outros genótipos de tangerinas, possivelmente devido à heterozigose das espécies genitoras destas duas variedades híbridas.

Uma maior dissimilaridade genética foi encontrada entre as espécies $\boldsymbol{C}$. medica (cidreira Of Comerce), $\boldsymbol{C}$. grandis (toranjeira Paraiso) e $\boldsymbol{C}$. latifolia (limeira acida Tahiti) (Figura 1). O coeficiente entre o grupo das tangerineiras e as outras duas espécies verdadeiras dos citros $(\boldsymbol{C}$. medica e $\boldsymbol{C}$. grandis) foi próximo de 0,6. Este índice foi superior ao índice de 0,27 encontrado por COLETTA FILHO et al. (1998). Esta diferença, possivelmente, deve-se ao coeficiente de similaridade utilizado neste trabalho, que considera as ausências de fragmentos como evidências de homologia e fornecem informações equivalentes as comparações presença/presença.

Os quatro cultivares de Citrus sinensis analisados ('Caipira', 'Valência', 'Cipó' e 'Pera do Rio') apresentaram similaridade máxima (100\%) mostrando que os oligonucleotídeos iniciadores utilizados não foram eficientes para detectar diferenças genéticas dentro desta espécie. $\mathrm{O}$ grau de similaridade encontrado neste estudo para as laranjeiras doce, que não permite a diferenciação entre os quatro cultivares analisados, está de acordo com aqueles encontrados por outros autores em estudos de diversidade genética para a espécie, com isoenzimas e marcadores moleculares (SAWAZAKI et al.,1992; LURO et al., 1995). As laranjeiras doce (C. sinensis. Osbek) apresentam uma estreita base genética, visto que, provavelmente a laranjeira doce seja um híbrido interespecífico (SCORA, 1975; 
BARRET \& RHODES, 1976) e a proliferação da maioria das variedades comerciais ocorreu pela seleção de mutações somáticas (HODGSON, 1967).

SAWAZAKI $\boldsymbol{e t}$ al.(1992), analisando sete sistemas enzimáticos para caracterizar espécies de citros de laranjeiras, tangerineiras, limeiras, limoeiros e Poncirus encontraram grande variabilidade genética interespecífica, porém não encontraram nenhuma variedade entre os cultivares de laranjeira doce ('Hamlin', 'Natal', 'Valência', 'Pineaple', 'Ruby', 'Moro' e 'Pera'). Segundo estes autores, a ausência de identificação pelas isoenzimas entre variedades de C. sinensis, apesar do número médios de alelos por loco e alta heterozigosidade, sugere que a origem da diversidade varietal pode ter sido decorrente de mutações.

Similarmente, LURO et al. (1995) usaram "primers" VNTR-PCR para avaliar a diversidade genética em tangerineiras e laranjeiras e não encontraram diferenças entre as 10 cultivares de laranjeira doce $(\boldsymbol{C}$. sinensis $)$ analisadas. Esses autores utilizaram minisatélites como oligonucleotídeo iniciador para avaliar a diversidade genética em laranjeiras doce, mas as sequências utilizadas não foram eficientes para detectar possíveis mutações responsáveis pela ampla variação presente nesta espécie.

Desta forma, os marcadores RAPDs utilizados neste trabalho, também não foram eficientes para distinguir variedades de laranjeiras doce. A discriminação de materiais muito aparentados, no entanto, pode ser alcançado quando se aumenta o número de bandas polimórficas, por meio do uso de um número maior de "primers" (WELSH et al., 1991; FERREIRA \& GRATAPAGLIA, 1995). Possivelmente, a utilização de um maior número de "primers", ou de outros marcadores moleculares, como microsatélites e AFLP aumentariam a probabilidade de se encontrar em sítios específicos das possíveis mutações de ponto ocorridas nesta espécie.

\section{AGRADECIMENTOS} pelo suporte financeiro.

Os autores agradecem à FAPERGS/RS e ao $\mathrm{CNPq}$

\section{REFERÊNCIAS BIBLIOGRÁFICAS}

BARRET, H.C., RHODES, A.M. A numerical study of affinity relationships in cultivated Citrus and its close relatives. Systematic Botany, Kent, v.1, p.105-136, 1976.

BASTIANEL, M., SCHWARZ, S.F., COLETA FILHO, H.D., $\boldsymbol{e}$ al. Identification of zygotic and nucellar tangerine seedlings (Citrus spp.) using RAPD. Genetics and Molecular Biology, Ribeirão Preto, v.21, n.1, p.123-127, 1998.
CAI, Q., GUY, C.L., MOORE, G.A. Extension of the linkage map in citrus using Random Amplified Polymorphic DNA e RFLP mapping of cold-acclimation-responsive loci. Theoretical Applied Genetics, Berlin, n.89, p.606-614, 1994.

CAMERON, J.W., FROST, H.B. Genetics, breeding and nucellar embryony. In: REUTHER, W., BATCHELOR, L.D., WEBBER, H.J. (Eds). The citrus industry. VI Berkeley : University of California, 1968. V.2. p.325-370.

COLETTA FILHO, H.D., MACHADO, M.A., TARGON, M.L. P.N., et al. Analysis of the genetic diversity among mandarins (Citrus spp.) using RAPD markers. Euphytica, Berlin. n.102, p.133-139, 1998.

FERREIRA, M.E., GRATTAPAGLIA, D. Introdução ao uso de marcadores RAPD e RFLP em análise genética. Brasília: EMBRAPA, 1995. 220p.

GREEN, R.M., VARDI, A., GALUN, E. The plastone of Citrus. Physical map, variation among Citrus and species and comparisom with related genera. Theoretical Applied Genetics, Berlin, n.72, p.170-177, 1986

HANDA, T., ISHIZAWA, Y., OOGAKI, C. Phylogenetic study of fraction I protein in the genus Citrus and its close related genera. Japan Journal of Genetics, Tokyo, n.61, p.15-24, 1986.

HODGSON, R.W. Horticultural varieties of citrus. In: REUTHER, W., BATCHELOR, L.D., WEBBER, H.J. (Eds). The citrus industry. VI Berkeley: University of California. 1967. p.431-591.

IWAMASA, M., NITO, N. Cytogenetics and the evolution of modern cultivated Citrus. In: INTERNATIONAL CITRUS CONGRESS, 6., 1988, Tel Aviv. Proceedings... Tel Aviv : International Society of Citriculture, 1988. v.1, p. 165-275.

LURO, F., BOVÉ, J.M., OLLITRAULT, P. DNA Amplified fingerprinting, a useful tool for determination of genetic origin and diversity analysis in Citrus. HortScience, Alexandria, v.30, n.5, p.1063-1067, 1995.

LURO, F., LAIGRET, F., BOVÉ, J.M. Application of random amplified polymorphic DNA (RAPD) to Citrus genetic and taxonomy. In: INTERNATIONAL CITRUS CONGRESS, 7, Italy, 1992. Proceedings... Italy : International Society of Citriculture, 1992. V.1, p.225-228.

MACHADO, M.A., COLETTA FILHO, H.D., TARGON, M.L.P.N., et al. Genetic relationships of Mediterranean mandarins (Citrus deliciosa Tenore) using RAPD markers. Euphytica, Berlin, n.92, p.321-326, 1996.

MURRAY, M.G., THOMPSOM. W.F. Rapid isolation of high molecular weight plant DNA. Nucleic Acids Research, n.8, p.432-435, 1980 .

ROHLF, F.J. NTSYS - PC numerical taxonomy and multivariate analysis system. Version 1.7. New York : State University of New York, 1992.

ROOSE, M.L., TRAUGH, S.N. Identification and performance of Citrus trees on nucellar and zygotic rooststocks. Journal of the American Society for Horticultural Science, Alexandria, v.113, n.1, p.100-105, 1988. 
SAMBROOK, J., FRITSCH, E.F., MANIATS, T. Molecular cloning: a laboratory manual. New York : Cold Spring Harbor Laboratory, 1989. Não paginado.

SAWAZAKI, H.E., SODEK, L., PIO, R.M. et al. Identificação de espécies de citros mediante polimorfismo enzimático. Bragantia, Campinas, v.51, n.2, p.121-128, 1992.

SCHAFFER \& SEDEROFF. Annal Biochem, n..115. p.113-122. 1989.

SCORA, R.W. On the history and origin of citrus. Bulletins of the Torrey Botanical Club, v.102, n.6, p.396-375, 1975.

SWINGLE, W.T, REECE, P.C. The botany of citrus and its wild relativies. In: REUTHER, W., BATCHELOR, L.D., WEBBER, H.J. (Eds). The citrus industry. Berkeley : University of California, 1967. p.190-430
TANAKA, T. Species problems in citrus. Tokyo : Japanese Society for the Promotion of Science, 1954. 152p.

TORRES, A.M., SOOST, R.K, DIEDENHOFEN, U. Leaf isozymes as genetic markers in citrus. American Journal of Botany, n.65, p.869-881, 1978.

WELSH, J. HONEYCUTT, R.J., McCLELLAND, M. et al. Parentage determination in maize hybrids using the arbitrarily primed polymerase chain reaction (AP-PCR). Theoretical Applied Genetics, Berlin. n.82, p.473-476, 1991.

YAMAMOTO, M., KOBAYASHI, S, NAKAMURA, Y., $\boldsymbol{e} \boldsymbol{t} \boldsymbol{a l}$. Phylogenic J. Citrus revealed by RFLP analysis of mitochondrial and chloroplast DNA. Japanese Journal Breeding, Tokyo, n.43, p.355-365, 1993.

Ciência Rural, v. 31, n. 5, 2001. 